\title{
OPTICAL IRIDECTOMY, INDICATIONS, METHOD AND VALUE
}

\author{
BY
}

\author{
J. Foster, F.R.C.S. \\ WEST HARTLEPOOL
}

ONE attraction of Ophthalmic Surgery, a compensation for its fickleness, lies in the sight-giving operations, lens extraction, and optical iridectomy, which are more dramatic in their results than those say for chronic glaucoma which are but a brake on a progressive disease.

Since its inception by Wenzel in $1871,{ }^{1}$ different writers on optical iridectomy,, $\mathbf{3 , 4 9}$ have mentioned that results are not so good as the mechanics of the operation might suggest. I have been unable to find in the literature, however, any series of cases that stress this or show just how much benefit one may expect. The 35 cases summarised in this paper represent four years work by the surgeons of the Royal Westminster Ophthalmic Hospital. No out-patient notes are available before this time.

\section{Indications}

The cases in which operation is indicated must have a percipient retina and can be divided into two classes.

1. Optical Obstruction only, of the pupil by opacities of the cornea or lens, more rarely by keratoconus, and dislocation of the lens.

2. Pupillary Deformation where the pupil is deformed by synechiae.

(a) Occlusio and seclusio pupillae with an intact lens form one group, and

(b) Drawing up of the pupil to the section after lens extraction forms the other.

In group (a) secondary glaucoma may provide an additional indication for iridectomy. Group $(b)$ is dealt with by iridotomy as a rule. In the four cases included an iridectomy proper was performed.

In Class I the opacity should be of a stationary nature. An exception to this may be made in ophthalmia neonatorum. Here it is customary to wait until the child is weaned to see how 
much will absorb. If, however, it is very dense and extensive, the operation may be performed as early as two months of age to prevent the onset of nystagmus. This complication, unfortunately, usually arises in the first six months of life, and rarely after two years. Iridectomy is much better as a prophylactic than as a cure. Where the opacity is progressive, as in cases where a preliminary iridectomy is performed for senile cataract, the optical effect is negligible, and out of 72 such cases in the past four years, not one shows any visual improvement. The opacity should of choice, be small, dense, and not surrounded by a nebulous area whether lenticular or corneal. In the lens, only small, axially situated, lamellar (or "Coppock") cataracts with a vision of less than 6/18 are suitable as a rule. Anterior polar cataracts rarely interfere enough with vision ; large lamellar cataracts occupy all but the periphery of the lens and require discission. Should no definite improvement in vision occur after a week's mydriasis, operation is contra-indicated. This test excludes cases with partly transparent opacities, insufficient clear cornea or lens, or defective retinae. Lamellar cataracts that do not improve to $6 / 18$ at least, should also be considered unsuitable.

The site of election for the coloboma is "down and in." This is alleged to be the area nearest to the visual axis. As the visual axis is in actuality $5^{\circ}$ "up and in," this site has probably been chosen empirically, and for cosmetic reasons. Frequently, the clearest portion of cornea as determined by ophthalmoscopy of the details of the optic disc is in another quadrant. The coloboma is then sited preferentially behind this. Even when the only available clear area is behind the upper lid, the coloboma may still be of use as the lid may be tonically raised to obtain a little vision if the sight is bad in the other eye. The lid may even serve to cut down dazzling. Where both eyes are defective a tenotomy of the superior rectus may place the clear area opposite the palpebral fissure. ${ }^{10}$ In a lamellar cataract, the best situation may be found by rotating a pear shaped stop $2.5 \times 1.5 \mathrm{~mm}$. in front of the dilated pupil. 4 . More ingenious variants of the same principle are a contact glass with a transparent sector, ${ }^{6}$ and a piece of black paper with a sector cut out and made adherent to the cornea by grease. ${ }^{14}$. The inventor of the latter method corroborates his results so obtained by an eccentric mydriasis. Injection of 0.3 c.c. of a standard solution of adrenalin or $\mathrm{m}$. ii of laevo-glaucosan (against which are strict injunctions on the leaflet) under the conjunctiva near the limbus, will produce an initial, local dilatation of the pupil towards the injection, giving the same optical effect as a temporary coloboma. 


\section{Method}

Class $1 .-$ There is a choice of three operations ${ }^{10 .}$

(1) Ectomia ex Iride cum Sphincterectomia.

(2) Ectomia ex Iride Simplex.

(3) Iridoto-Iridectomedialysis.

In method (1) the coloboma should be narrow, continuous with the pupil, uncovering lens only and not the zonule. If its outer limit can be kept within the "collarette" and yet not be covered by the opacity so much the better. It is made by a keratome incision just inside the limbus, withdrawing the iris by traction directly on the pupil margin wih forceps or an iris hook, and excising the iris with de Wecker's scissors held radially. Preoperative miosis will shorten, and mydriasis lengthen the slit produced.

This operation is useful in the small central corneal opacities, but is specially indicated in lamellar cataracts and to increase the lens-free area of the pupil in congenital dislocation of the lens.

Method (2) is used in larger corneal opacities with a very dense centre and a less dense periphery. A small area of iris is withdrawn through a keratome wound with Hess's forceps from behind the clear area of cornea and excised, leaving the sphincter intact. The dense central area obviates uniocular diplopia.

Method (3) is employed where a small sickle-shaped area of cornea alone remains clear. Irido-dialysis is produced by insertion of a narrow keratome near the centre of the corneal scar, the iris being seized about $1 \mathrm{~mm}$. from the limbus, gradually drawn out with an oscillating movement and divided. This operation which is very similar to one devised by Mayou for adherent leucomata, has very little effect from the optical point of view, and its value is mainly therapeutic. ${ }^{10 .}$

These operations may be done under a local anaesthetic in the adult if cocaine is inserted frequently for 20 minutes, but are painful at moments of tension on the iris, and are more easily carried out under general anaesthesia.

Tattooing may be employed as an adjunct to optical iridectomy, and its probable efficacy in a given case estimated by application of black paper to correspond with the area to be tattooed.8. It is extremely rare for anything but a cosmetic effect to be produced.

Class II A.-The problem here is to remove the iris without producing a traumatic cataract. It has been suggested with this danger in mind that the iridectomy be made at " 12 o'clock" where it would assist a subsequent cataract extraction. ${ }^{5 .}$ Apart from adherent leucomata where the method of $\mathrm{Mayou}^{13}$ is indicated, there are three methods available. 
(1) Iridorrhexis (Desmarres) consists of tearing away the iris near the pupillary margin with forceps, and, if possible, excising it. Margennis ${ }^{12}$ describes a good result from this method. As the iris is friable it is difficult to get a good purchase on it, and in addition the pigment layers may remain adherent to the lens. When the iris is "bombé," it is the flattest and apparently most suitable areas that suffer from this disadvantage. Where the bulging forward of the iris is very marked, Fuchs' transfixion operation may have to be done to render an iridectomy feasible. ${ }^{7}$

(2) The method ascribed by Grimsdale to Brudenell Carter.8. This requires insertion of Carter's scissors through a keratome wound opening the blades flat against the iris, and snipping off the bulge rising between them. Two satisfactory cases are described by this author.

(3) Where the lens may be cataractous and shrunken as in old "sympathising" eyes, a conjunctival flap and keratome incision may be made as for anterior sclerotomy "up and out." The sharp pointed blade of de Wecker's original scissors is then introduced through this, pushed through and behind the iris and across the face of the lens. The blunt-ended blade is in the anterior chamber, and when the instrument is closed an oblique slit in the iris is produced. Case No. 30 was dealt with in this way producing an adequate pupil. The lens remains to be dealt with.

Group II B.--Iridectomy should not be attempted for a year after the lens extraction, when uveal inflammation has subsided, as shown by absence of endothelial oedema of the cornea.

An incision is made at "six o'clock" just inside the limbus with a Taylor's knife. This is passed vertically upwards about $2 \mathrm{~mm}$. across the anterior chamber, then through the iris and up behind it into the drawn up pupil. The knife is withdrawn and a malleable hook passed along its track, until it engages in the pupil margin which is drawn outside the wound, and the iris divided with de Wecker's scissors. For convenience in manoevering the hook, the shaft should be bent at right angles before insertion as suggested by Sir Richard Cruise. A large vertical opening is thus produced, but even this may contract down, and the operation also suffers in common with iridotomy the disadvantage of unabsorbed haemorrhage into the vitreous, hernia through the new pupil, and opacities into the vitreous behind from preceding inflammation.

\section{Results}

To assess results, cases must be divided into two classes. Operations of "Election," where vision in the other eye is good, and operations of "Necessity" where vision in both eyes is poor. 
Class I 12 cases.

Elective 5 cases. Improved, none.

Necessitous 7 cases. Improved, Nos. 1, 8, 10.

Class II 19 cases.

Elective 5 cases. Improved, No. 26.

Necessitous 3 cases. Improved, Nos. 14, 19, 23 tem-

No. 28 slightly.

porarily.

Nos. $31,27,18$ greatly.

Class II $B \quad 4$ cases.

Necessitous 4 cases. Improved, Nos. 33 and 34.

That is to say of 10 "Elective" cases, only one showed any improvement and that but slight. Since every operation of this nature exposes the sound eye to a risk admittedly remote of sympathetic ophthalmitis, and the bad eye to the possibility of dazzling or uniocular diplopia, it is suggested that to avoid unnecessary operations in Class I, "considerable" improvement be insisted upon when the pupil is dilated, before operation be performed. As a standard, an improvement of H.M. to identification of the letters of "6/24" Snellen at 2 feet is suggested as compatible with the word considerable. Uniocular lamellar cataracts, which are extremely rare, might be considered under this standard instead of that demanded for the bilateral variety. Mayou ${ }^{\mathbf{1 3}}$ has already pointed out that if vision in one eye is good, the most that can be hoped for by operating on the other is "increased vision for large objects." It might here be pointed out that the vision after optical iridectomy may continue to improve for two months after operation, as the patient gets used to the coloboma.

In assessing the visual results in the "necessitous" cases one must consider, in addition, factors other than the visual acuity.

Lawson $^{11}$ has pointed out that the merest scintilla of sight may be a disadvantage to a man who would otherwise be reconciled to stone blindness, At the same time an increase in vision from $\mathrm{P}$. $\mathrm{L}$. to counting fingers may make an enormous difference to a determined individual. In general the value of the operation to the patient varies inversely as his pre-operative visual acuity, and directly as his applied intelligence. In the most successful cases functionally in Class II, the highest recorded final vision was $6 / 36$, but in some of them an increase to 6/60 was enough to change the patient's mode of life completely. 9 cases out of 30 in the "necessitous" class showed some improvement. Butler ${ }^{2}$ has said of this class that the most one can hope for is to give enough sight for the patients to get about. 
In general, in this series, the least successful are the cases of corneal opacity. The most successful visually, are lamellar cataract, and functionally occlusio pupillae.

Of the whole series, 9 out of 35 showed varying degrees of permanent improvement.

The highest permanent vision produced by the operation was $6 / 24$. In Class II $B$. the results produced by iridectomy were rather better than those in the nine cases of iridotomy, performed for the same condition during the same period. I have been unable to include a case of ophthalmia neonatorum as the only case on which optical iridectomy was performed during this period was that of a mentally deficient child whose vision cannot be estimated. It does not appear to be improved.

Results in general in ophthalmia neonatorum are most disappointing; this is unfortunate as they are almost always of the "necessitous" type. The highest visual acuity obtained in such a case that $I$ have been able to ascertain is $6 / 36$.

My thanks are due to Mr. Grimsdale and Mr. McMullen for revising this paper, and to the surgeons of the Royal Westminster Ophthalmic Hospital for permission to publish these cases.

\section{Class I}

\section{O.I.=Optical Iridectomy}

1. Aged 55 years, Tool setter. Developed pannus of unknown aetiology that partly covered pupils from 7 years of age. Learnt his trade while both eyes were atropinised. Developed mydriatic irritation. Double optical iridectomy enabled him to carry on for $2 \frac{1}{2}$ years more; until the present curious superficial keratitis covered both iridectomies.

2. Aged 73 years. Corneal ulcer lasting a month.

Rt. Lens opacity 6/36.

Lt. Adherent leucoma. Good projection O.I. Not improved.

3. Aged 17 years. Scholar. "Eyes were bad following whooping cough."

Lt. Phthisis bulbi.

Rt. Cornea nebulous. H.M. Optical iridectomy attempted. Not improved.

4. Aged 49 years. Housework. Interstitial keratitis and choroiditis 13 years ago.

Lt. Nebulous cornea. Old k.p. pupil normal H.M.

Rt. " , ", , " , " , O.I.

Less than" 6/60-nö improvement recorded."

5. Aged 26 years. Ship's steward. Knocked his eye on a ship's bolt.

Rt. Normal 6/9.

Lt. Large nebula. H.M. at 1 foot. O.I. Not improved.

6. Aged 50 years. Labourer. Herpes ophthalmicus.

Rt. Dense leucoma; superficial vascularisation $6 / 60$. O.I. Not improved.

Lt. Amblyopic since birth 6/60. 
7. Aged 47 years. Cracker maker. Silver nitrate and nitric acid mixture boiled up into his eyes, 1 year ago.

Rt. Symblepharon, dense corneal opacity below and axially. Counts fingers $1 \mathrm{ft}$. O.I. Not improved.

Lt. Dense opacities below and to temporal side, cornea clear above. C.F. $2 \mathrm{ft}$. O.I. Not improved.

8. Aged 52 years. Civil servant. Ten years failure of sight.

Lt. Lamellar cataract. 3/60. -O.I. $6 / 24$.

Rt. ". ", 6/24. O.I. 6/36.

9. Aged 26 years. Gardener. Corneal ulcer in third week of smallpox.

Rt. Normal. $6 / 6$.

Lt. Dense leucoma. Good projection. O.I. Not improved.

10. Aged 58 years. Farmer. Recurrent corneal ulceration.

Rt. Vascularised nebula. H.M. O.I. 6/24.

Lt. ", but less dense nebula. H.M. O.I. 6/60.

11. Aged 32 years. Clerk. Four months corneal ulceration.

Lt. Normal 6/5.

Rt. Dense leucoma. C.F. at $1 \mathrm{ft}$. O.I. C.F. at 18 ins. No improvement.

12. Actor. Corneal ulcer requiring peritomy 2 years ago.

Lt. Normal 6/9.

Rt. Dense vascularised nebula. C.F. at $2 \frac{1}{2} \mathrm{ft}$. O.I. "Diplopia and haloes,round lights." C.F. at $1 \frac{1}{2} \mathrm{ft}$., but "feels that sight is improved."

\section{Class II $a$}

13. Aged 40 years. Jeweller. Recurrent iridocyclitis.

Rt. Partial seclusio pupillae. 6/24. O.I.
Lt. Seclusio and occlusio pupillae. Bare P.L.

14. Aged 66 years. Teacher. Scleritis 45 years ago.

Rt. Corneal opacities and post synechiae $<6 / 60$.

Lt. " . " . . . . . 6/36. O.I. 6/24 later fell to $6 / 60$.

15. Aged 56 years. Porter. Iridocyclitis 20 years.

Rt. A little débris in pupil. 6/9.

Lt. Occlusio pupillae. P.L. O.I. Not improved.

16. Aged ? years. Housework. Two years recurrent iritis.

Lt. Post. synechiae. $6 / 9$.

Rt. ." ., 6/60. O.I. Not improved.

17. Aged 38 years. Tuberculous iridocyclitis and phthisis 8 years.

Lt. Exudate and new blood vessels in pupil. Poor projection. O.I.

Rt.

Not improved.

Good projection. O.I. Not improved.

18. Aged 48 years. School teacher. Eight years ago tuberculous iridocyclitis and corneal ulceration.

Lt. Dense leucoma, post. synechiae. Poor projection, O.I. Not improved-later excised.

Rt. Dense leucoma, post. synechiae. Good projection. O.I.<6/60.

"But able to get about which she has not done for years. Very grateful." 
19. Aged 11 years. School boy. Attending hospital since $4 \frac{1}{2}$ with interstitial keratitis.

Rt. Big nebula covering seclusio pupillae $<6 / 60$. O.I. '29 6/18.

Lt. $\quad<6 / 60$. O.I. '29 6/36. ' 31 sight has "since failed. ? Retinal detachment and now can just tell night from day.

20. Aged 34 years. Housework. Perforating wound 24 years ago.

Rt. Normal eye 6/5.

Lt. Adherent leucoma. P.L. O.I. Not improved.

21. Aged 56 years. Housework. Iridocyclitis both eyes 1 year ago.

Lt. Large corneal leucoma. C.F. at $2 \mathrm{ft}$.

Rt. ", ", C.F. at $2 \mathrm{ft}$. O.I. Not improved.

22. Aged 71 years. Labourer. Iridocyclitis.

Lt. Phthisis bulbi.

Rt. Seclusio pupillae. H.M. at $2 \mathrm{ft}$. Optical iridectomy. H.M. vectis extraction of lens with iridectomy R.V.=P.L.

23. Aged 42 years. Labourer. "As an infant had inflammation of the eyes."

Rt. Extensive ant. staphyloma. P.L. later excised.

Lt. Central corneal nebula and post. synechia $6 / 60$. O.I. 6/36 but later fell to $6 / 60$.

24. Aged 28 years. Housework. Iridocyclitis (? tuberculous) 4 years ago.

Rt. Diffuse corneal haze, iris bombé C.F. at 1 metre. Operation, 6/60.

Lt. " " . " " , H.M. Operation, 6/60.

25. Aged 52 years. Hotel porter. Several attacks of iritis during 10 years.

Rt. Small nebulae and almost complete seclusio pupillae. Vitreous opacities $4 / 60$ operation, C.F. $2 \mathrm{ft}$.

Lt. Small nebulae. Post. synechiae. Contracted field 6/36 operation, not improved.

26. Aged 62 years. Labourer. Hypopyon ulcer 9 months ago.

Rt. Normal eye 6/9.

Lt. Leucoma and post. synechiae $<6 / 60$ operation. "Peripheral vision improved."

27. Aged 31. Knitter. Interstitial keratitis at 8 years of age.

Rt. Seclusio and occlusio pupillae: Transverse calcareous band C.F. at 6 in. operation, C.F. at $1 \mathrm{ft}$.

Lt. Seclusio and occlusio pupillae. Transverse calcareous band H.M. operation, 6/60 "Is able to get about better and was able to read a letter. She has not done this for years."

28. Aged 26 years. Blind school boy. Old interstitial keratitis.

Rt. Hazy cornea. 6/36 operation, 6/36.

Lt. " ." Iris bombé. 6/60 operation, 6/36.

29. Aged 51 years. Housework. Old corneal ulceration.

Lt. Adherent leucoma. $6 / 60$ operation, $6 / 36$.

Rt. Normal eye. 6/5 partly.

30. Aged 16 years. Blind school. Perforating injury of L. eye when a child. "Sympathetic" in L. eye.

Lt. Phthisis bulbi.

Rt. Corneal calcareous opacity. Occlusio pupillae. T. $-1, \mathrm{H} . \mathrm{M}$. at 6 in. Iris divided by de Wecker's scissors inserted through a keratome wound. Lens now visible.

31. Aged 19 years. Knitter. Old interstitial keratitis.

Lt. Dense corneal opacity chiefly central. Iris bombé H.M. Iridectomy $6 / 36$ and J.2 at 4 in.

Rt. Dense corneal opacity chiefly central. Iris bombé H.M. Iridectomy H.M. "The operation enabled her to get about. Both eyes have been trephined since." 


\section{Class II $b$}

\section{Complicated after cataract}

32. Aged 66 years. Housework Old glaucoma and lens extraction. July, ' 31 . Lt. Anophthalmos.

Rt. Pupil drawn up and capsule unchanged by capsulotomy P.L. October, 1929. Iridectomy, leaving a fair sized pupil, C.F. at 1 metre. Pupil contracted, March, 1930. Iridectomy. No elasticity in iris at all, tore on insertion of hook leaving a vertical slit that soon closed. Doubtful P.L.

33. Aged 49 years. Carpenter. Tuberculous iridocyclitis 2 years.

Rt. Post. synechiae and cataract. H.M. (Active iridocyclitis.)

Lt. " " , " C.F. at 9 ins. June, 1931. Lens "extraction. Pupil drawn up to section. V.=P.L. August, 1931. Iridectomy, $\mathrm{V}=6 / 60$. "Patient can get about by himself. Had previously been signed up as a blind person at another hospital and told nothing could be done."

34. Aged 48 years. Violinist. Recurrent iritis, iridectomy 6 years ago.

Rt. Post. synechiae, lens opacities. C.F.

Lt. . " " Pupil blocked wiih exudate, opaque lens. H.M. "March," 1931. Synechia divided. Lens extraction. Pupil subsequently pulled up. $=$ C.F. at $3 \mathrm{ft}$. February, 1932. Iridectomy. Good pupil. $6 / 36$ and J.14. Retinal and choroidal haemorrhages. Much improved visually.

35. Aged 76. Housework. Rt. lens extraction. January, 1931. Delirious after operation. Prolapse.

Lt. Lens opacities. $6 / 18$ later fell to $6 / 60$.

Rt. Old prolapse, pupil drawn up and contains exudate. November, 1931. Iridectomy. Good opening made but blood stained vitreous blocks it, and it is contracting. Good projection.

In all cases quoted above the vision is the best obtainable with correction.

\section{REFERENCES}

1. Alt, A.-Syst. Ophthal. Op. (Wood), Vol. II, pp 1024-1063, 1911.

2. Butler, H.-Trans. Ophthal. Soc U.K., p. 38, et. seq., 1922.

3. Clark, S.-Ind. Med. Gaz., Vol. LI, p. 194, 1916.

4. Fuchs, E.-Text Book of Ophthalmology, pp. 906-908, 1924.

5. Idem., p. 439, 1924.

6. Gradle, S.-Trans. Amer. Acad. Ophthal. and Oto-Laryngol., 17 Bis. October 22, 1921.

7. Green, J.-Ainer. Jl. of Ophthal., pp. 657-660, 1927.

8. Grimsdale, H. and Brewerton, E.- "Ophthalmic Operations," p. 387.

9. Grimsdale, H. B.-Med. Press and Circ., N.S. LXXVIII, p. 94, 1904.

10. Kuhnt, H.-Zeitschr. f. Augenheilk., Vol. X, pp. 219-234, 1903.

11. Lawson, A. - "War Blindness at St. Dunstan's," p. 131.

12. Magennis, E.-Lancet, Vol. II, p. 1181, 1905.

13. Mayou, M. S.-Trans. Ophthal. Soc. U.K., p. 38, et. seq., 1922.

14. Vannas, M.-Klin. Monatsbl. f. Augenheilk., Vol. LXXXIII, pp. 476-482.

15. Roche, C.-Arch. d'Ophthalmologie, p. 825, tom 48, December, 1931.

Since writing this paper another article on the subject has come to my notice. ${ }^{15}$ The author, Roche, quotes cases in which the cornea cleared to a surprising extent, and the artificial coloboma was a liability to the patient by reason of the dazzling produced. This occurred although the operation was technically perfect when originally performed. He emphasises that although an eye might see better with an iridectomy, it is the patient's ultimate benefit and not this alone that should be considered in deciding for or against operation. 